\title{
Without a NULL That String Would Never End
}

Stan Kelly-Bootle, Author

t's an undiluted pleasure to be invited to contribute a third column for ACM Queue under the surly rubric "Curmudgeon." Curmudgeons are not usually associated with pleasures, diluted or full strength, but at my age the cheap thrill of thrusting a poisoned pen is especially welcome since the targets for satire bob daily as upstart sitting ducks for the roasting: mere "Juvenal delinquents," as master curmudgeon George Crabbe [sic] called them.

My first snipe is at those mathematicians who are over-fond of redefining everyday concepts to remove possible ambiguities, yet not always successfully. Thus, the "streak" of the sports-stats lexicon means any decent run of victories (or defeats). The formal definition of an $\mathrm{N}$ streak for a given event-type, E, permits $\mathrm{N}$ to assume any non-negative integer. The abstract 0 -streak differs from no streak at all, just as the empty set is far from null in the usual sense of "lacking substance."

In fact, the empty set is truly unique (if you've seen one of them, you've seen them all) in that it has, according to the APL (as in SIGAPL) guru, Edward M. Cherlin, "the Zen power to generate endless koans, including the whole of mathematics." Mike Rejsa claims that the importance of null may be deduced from the number of synonyms you meet when programming: "'; "; NULL; 0; OL; 'IO'; (int *)0; FALSE; and so on. (More recently, Bjarne Stroustup and Herb Sutter have finally tidied up a nagging technical quirk in ANSI/ISO C++. A new reserved keyword_nulptr_is being added to the standard to handle unambiguously the "null pointer,"-i.e., a pointer guaranteed not to point at anything.)

This approach echoes the widely believed but dubious Sapir-Whorf hypothesis: "We see and hear very largely as we do because the language habits of our community predisposes certain choices of interpretation." (Sapir, Edward. The Status of Linguistics as a Science, 1929). The related notion that the Inuit (never say Eskimo) have an unusually large number of "words" for snow persists in spite of detailed refutation of Sapir by Martin, Pullum, Pinker, and many other sociolinguists.

We must also allow the 1-streak, although this is nothing the average sports fan would boast of, except perhaps as a joke. If my rival, hated soccer team Everton FC man-

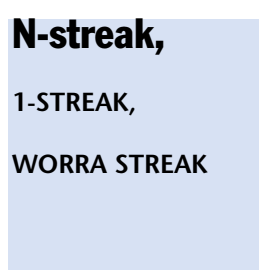

$$
\begin{aligned}
& \text { ages an isolated jammy } \\
& \text { win, we mock them: } \\
& \text { "Worra streak!" ("What a } \\
& \text { streak!" to the Scouse- and }
\end{aligned}
$$

Cockney-challenged.) With typical metamathematical exuberance we can consider the Event F, defined as NOT(E), or even take a streak $\mathrm{S}$ as a well-defined Event. Thus, we arrive at streaks of streaks (nested forever), not excluding streaks of 0 -streaks which, I'm told, Red Sox fans are certain will end next October.

May we posit $\mathrm{N}$-streaks with $\mathrm{N}<0$ or $\mathrm{N}$ non-integral? Forget mundane macro-reality, let's see where the sums lead. Many events are not directly observable, nor their occurrences counted 0, 1, 2, 3.... Dirac and Feynman showed that extending definitions counterintuitively (negative energy and time-reversals) can reveal unexpected, verifiable physical results. A trusted litmus test for your future in these exotic domains is your reaction to Rudy Langer's theorem: " $2+2=5$ for sufficiently large values of $2 . "$

Meanwhile my ACM Queue columny hits a promising 3-streak (also known as a "threepeat") thanks to editorial tolerance and reader-feedback encouragement. Almost hidden in the deafening applause is a mixed response from a "guest" (a.k.a. anonymous) poster to our forum. I mention it only because she/he wrongly imputes the stylistic influence of a Jorje Luis Borges and accuses me of "flooding the reader with obscure references" rather than "communicating ideas." Well, "Jorje" would itself be rather obscure to many even if "Jorge" were intended. As Lena Horne might have sung, "It Takes Two to Tangle," namely, the "writer-obscurer" and the "reader-obscured."

Much hinges on context, of course, and the broad spectrum of writing range from extreme obscurantism, via middle-road technical exposition, and on to what is often unfairly maligned as "dumbing-down." I've covered all these tracks in my 50-plus years of scrivening. Each category depends on subjective judgments, since authors/ editors can only guess their readers' pre-knowledge. The same problem is agonizingly apparent in teaching generally and especially (also from personal experience) in

Continued on page 79 


\section{Continued from page 80}

computer conference seminars. Indeed, the Mathematical Association of America's MathFest (Rhode Island Convention Center, August 12-14, 2004) will devote a whole session to the pedagogical challenges of a heterogeneous audience.

Here's a ploy that worked for a German language course I attended at Vienna University. The lecturer delivered a series of progressively more difficult paragraphs in German. We were asked to stand up as soon as we failed to understand the spiel. Assistants then guided us to the class appropriate to our level of comprehension. Could this "self-grading" work in other contexts? Interactive computer distance-learning allows similar strategies, but for written content the prospects are less promising: steering between puzzling the "slow" and boring the "smart."

The huge success of the Dummies series (triggered by Dan Gookin's DOS for Dummies, IDG Books, 1991) proves that "dumbing-down," if done well, pays off. Jealous cynics, including me, were quick to mock. We called them "Books for the Baffled" and "Low-Self-Esteem Texts," imagining guilt-ridden, shifty buyers such as those who whisper at the pharmacy for Grecian Formula or Preparation H. We invented scurrilous counter-titles like Visual Basic for the Blind, MIDI for the Deaf, Pacsal for the Dyxlesic, Quicken for the Dead, LISP for the Listless, and C++ for the Nonplussed. Other publishers tried to match the "Dummies" template with "X for Idiots," and even "X for Complete Idiots," but for some reason "Idiot" was perceived as more insulting than "Dummy." $Q$

\section{LOVE IT, HATE IT? LET US KNOW}

feedback@acmqueue.com or www.acmqueue.com/forums

STAN KELLY-BOOTLE http://www.feniks.com/skb/ http: //www.sarcheck.com, born in Liverpool, England, read pure mathematics at Cambridge in the 1950s before tackling the impurities of computer science on the pioneering EDSAC I. His many books include The Devil's DP Dictionary (McGrawHill, 1981) and Understanding Unix (Sybex, 1994). Under his nom-de-folk, Stan Kelly, he has enjoyed a parallel career as a singer and songwriter.

@2004 ACM 1542-7730/04/0700 \$5.00 